\title{
EFFECT OF TUBE PITCH ON HEAR TRANSFER IN SPRINKLED TUBE BUNDLE
}

\author{
Petr KracíK*， JiŘÍ PosPÍŠIL \\ Department of Power Engineering, Energy Institute, Technická 2896/2, Brno 616 69, Czech Republic \\ * corresponding author: kracik@fme.vutbr.cz
}

ABstRaCt. Water flowing on a sprinkled tube bundle forms three basic modes: the Droplet mode (the liquid drips from one tube to another), the Jet mode (with an increasing flow rate, the droplets merge into a column) and the Membrane (Sheet) mode (with a further increase in the flow rate of the falling film liquid, the columns merge and create sheets between the tubes. With a sufficient flow rate, the sheets merge at this stage, and the tube bundle is completely covered by a thin liquid film). There are several factors influencing both the individual modes and the heat transfer. Beside the above-mentioned falling film liquid flow rate, these are for instance the tube diameters, the tube pitches in the tube bundle, or the physical conditions of the falling film liquid. This paper presents a summary of data measured at atmospheric pressure, with a tube bundle consisting of copper tubes of 12 millimetres in diameter, and with a studied tube length of one meter. The tubes are situated horizontally one above another at a pitch of 15 to $30 \mathrm{~mm}$, and there is a distribution tube placed above them with water flowing through apertures of $1.0 \mathrm{~mm}$ in diameter at a $9.2 \mathrm{~mm}$ span. Two thermal conditions have been tested with all pitches: $15^{\circ} \mathrm{C}$ to $40^{\circ} \mathrm{C}$ and $15{ }^{\circ} \mathrm{C}$ to $45^{\circ} \mathrm{C}$. The temperature of the falling film liquid, which was heated during the flow through the exchanger, was $15^{\circ} \mathrm{C}$ at the distribution tube input. The temperature of the heating liquid at the exchanger input, which had a constant flow rate of approx. 7.2. litres per minute, was $40^{\circ} \mathrm{C}$, or alternatively $45^{\circ} \mathrm{C}$.

KEYwORDS: sprinkled; tube bundle; heat transfer; tube pitch.

\section{INTRODUCTION}

A liquid flowing through a horizontal tube bundle may form three basic sprinkle modes visible in Figure 1 These are the Droplet mode $(\mathrm{D})$, the Jet mode $(\mathrm{J})$ and the Membrane (Sheet) mode (S) [1-4].

With an increasing flow rate of the falling film liquid, the transition from the Droplet to the Jet mode is defined by the formation of one stable column of liquid among the droplets (this transition mode will be hereinafter referred to as the " $\mathrm{D} \rightarrow \mathrm{J}$ " mode). The transition from the Jet to the Membrane (Sheet) mode is defined by the connection of two columns and their formation of a small triangular sheet (hereinafter referred to as the " $\mathrm{J} \rightarrow \mathrm{S}$ " mode). In this mode, columns and sheet exist side by side.

With a decrease in the flow rate of the falling film liquid, the reverse process takes place. The formation of a stable liquid flow among the sheets is referred to as the Sheet-Column state (hereinafter referred to as the "S $\rightarrow \mathrm{J}$ " mode), and the disintegration of the first column in the Column mode and its replacement by droplets changes the state to the Jet-Droplet mode (hereinafter referred to as the " $\mathrm{J} \rightarrow \mathrm{D}$ " mode).

There are several factors influencing the individual mode types as well as heat transfer. Beside the above mentioned falling film liquid flow rate (tested [5] for example) they are for instance tube diameters (tested [6] for example), tube pitches in a bundle (tested [7] for example) or a physical condition of a falling film liquid and heat transfer (tested [8-10] for example).

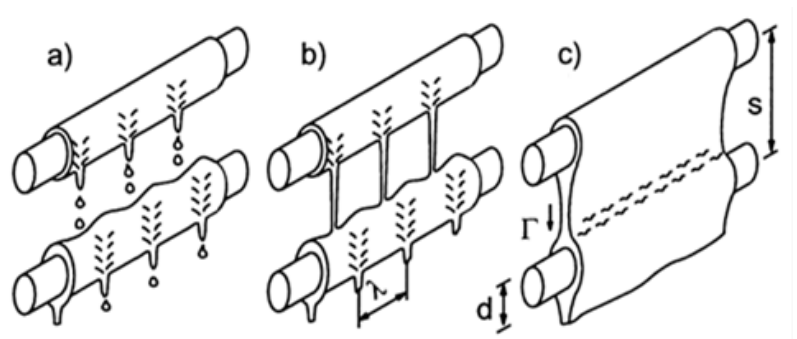

Figure 1. Sprinkle Modes [1.

The following results compare with those authors must be judiciously. For the authors of its results achieved under strict laboratory conditions for one to three trumpets and our research deals with the behavior "big tube bundle".

\section{EFFECTS OF PITCH TUBES ON A FALLING FILM LIQUID}

The influence of the gap between the sprinkled profiles on the flow mode was tested by Wang et al. [7. The tested bundle consisted of a distribution tube out of which a liquid was flowing (the tested substances were ethylene glycol and water), a tube of circular crosssection, whose purpose was to regulate the distribution of the falling film liquid, and of two flat tubes which created a gap that demonstrated the flow mode. The tested flat tubes were made of polished aluminium and had the following dimensions: $400 \times 25.4 \times 3.18 \mathrm{~mm}$ 


\begin{tabular}{|c|c|c|c|c|c|c|c|c|}
\hline \multirow{2}{*}{$\begin{array}{c}\mathrm{s}-\mathrm{D} \\
{[\mathrm{mm}]}\end{array}$} & \multicolumn{4}{|c|}{ Increasing flow } & \multicolumn{4}{|c|}{ Decreasing flow } \\
\hline & $\mathrm{D} / \mathrm{D}-\mathrm{J}$ & $\mathrm{J}-\mathrm{D} / \mathrm{J}$ & $\mathrm{J} / \mathrm{S}-\mathrm{J}$ & $\mathrm{S}-\mathrm{J} / \mathrm{S}$ & $\mathrm{S}-\mathrm{J} / \mathrm{S}$ & $\mathrm{J} / \mathrm{S}-\mathrm{J}$ & $\mathrm{J}-\mathrm{D} / \mathrm{J}$ & $\mathrm{D} / \mathrm{D}-\mathrm{J}$ \\
\hline 4.8 & 203 & 259 & 363 & 395 & 395 & 365 & 268 & 209 \\
\hline 6.4 & 231 & 293 & 390 & 427 & 429 & 389 & 289 & 230 \\
\hline 9.5 & 230 & 298 & 430 & 459 & 461 & 427 & 297 & 227 \\
\hline 14.5 & 244 & 320 & 435 & 473 & 470 & 426 & 328 & 236 \\
\hline 19.4 & 262 & 336 & 434 & 481 & 486 & 431 & 335 & 262 \\
\hline 24.5 & 268 & 348 & 448 & 512 & 513 & 449 & 341 & 264 \\
\hline RMS [\%] & 13.15 & 13.15 & 0.84 & 13.15 & 0.87 & 0.77 & 13.15 & 13.15 \\
\hline
\end{tabular}

TABle 1. Reynolds Numbers for Various Tube Pitches According to Wang et al. [7.

(length $\times$ height $\times$ width). The measuring itself was preceded by a 2 - to 3 -hour tube sprinkling which ensured an ideal adherence of the liquid to the surface (making the surface ideally wettable). The measurement procedure was followed to decrease the flow rate from the maximum value. After a zero flow rate had been reached, it was again increased to the maximum possible rate. The measurement was repeated three times for each profile gap, and only after these results were obtained, the Reynolds numbers for the given mode transition and the relative error of these values were determined.

Table 1 provides an overview of the measurement results where water with approximately the same physical properties, as those which were expressed by the authors by means of the modified Galilei number $\mathrm{Ga}^{0.25} \approx 450$, was used as the falling film liquid. This value at atmospheric pressure (101 325 $\mathrm{Pa})$ corresponds with a water temperature of approx. $27.4^{\circ} \mathrm{C}[11$.

To achieve the given measurement results, the authors [11] set the gap between the stabilization tube and the first profile to $2.0 \mathrm{~mm}$. Their results suggest that the larger the gap between the sprinkled profiles, the higher the Reynolds number for the given sprinkle mode. This increase, however, did not prove to be steady, as in one case of the gap increase the next Reynolds number was even lower by approx. 1.0\% which does not seem to be a correct value. The increasing gap causes the horizontal sprinkled diameter to increase as well and therefore more liquid. Higher flow rate, is necessary at a larger gap in order to achieve the same sprinkle mode. When comparing the Reynolds numbers belonging to the smallest and the largest gaps between the profiles at individual modes, the increase ranges between approx. $23 \%$ and $32 \%$. The difference in the Reynolds numbers between the increasing and decreasing flow rates at individual states equals on average $1.1 \%$, with a standard deviation of $1.1 \%$.

\section{MeAsuring apparatus}

For the purpose of examining the heat transfer and the sprinkle modes on sprinkled tube bundles, a test apparatus has been constructed; see the diagram in
Figure 2 on the right and the photograph of the apparatus on the left.

Falling film liquid of temperature (T1) and of volumetric flow rate (V1), which is measured by the FM1 FLOMAG 3000 induction flow meter, flows from a distribution tube positioned above the bundle to which a liquid of temperature (T3) and flow rate (V2), which is measured by the FM2 - FLOMAG 3000 induction flow meter flows in, and a liquid of temperature (T4) flows out into the collection flume positioned below the examined exchanger. The studied area (i.e., the sprinkled area), is one meter wide. There are also four thermocouples (T6-T9) in the loop measuring the process of temperature change within the loop. Below the exchanger, falling film liquid is collected into a small flume situated right below the last tube, from which the liquid is conducted towards the thermocouple (T4), which measures its temperature. The liquid then freely flows into the collection flume, from which it is drawn by a pump into a drain (C). In case of excess hot water, it can be let off to a drain through a gate valve (GV6). The sprinkling loop is further fitted with a water meter and a rotameter for the purpose of visual inspection. All the thermocouples are insulated and unearthed $\mathrm{T}$ type thermocouples.

All examined liquid temperatures (T1-T9), the environment temperature (uninsulated $\mathrm{T}$ type thermocouple) and flow rates V1 and V2 are continuously recorded by DAQ 56 converters and saved in a computer in the LabView interface.

Apart from the effect the flow rate of the falling film liquid has on the examined heat transfer, the influence of the tube surface has also been studied. In Figure 3, on the left, a clear difference between the smooth surface and the grooved surface with a rhombus pattern is visible. This surface has been created using the cold volumetric profiling and track wheeling technique (grooving). The outer tube diameter ranges from 12.3 to $12.4 \mathrm{~mm}$. The calculations take into account the mean tube diameter, which is $12.0 \mathrm{~mm}$. In Figure 3, on the right, we can see an example of the difference between the smooth and sandblasted surface.

The calculation of the heat transfer coefficient in this paper is based on the thermal balance according to 

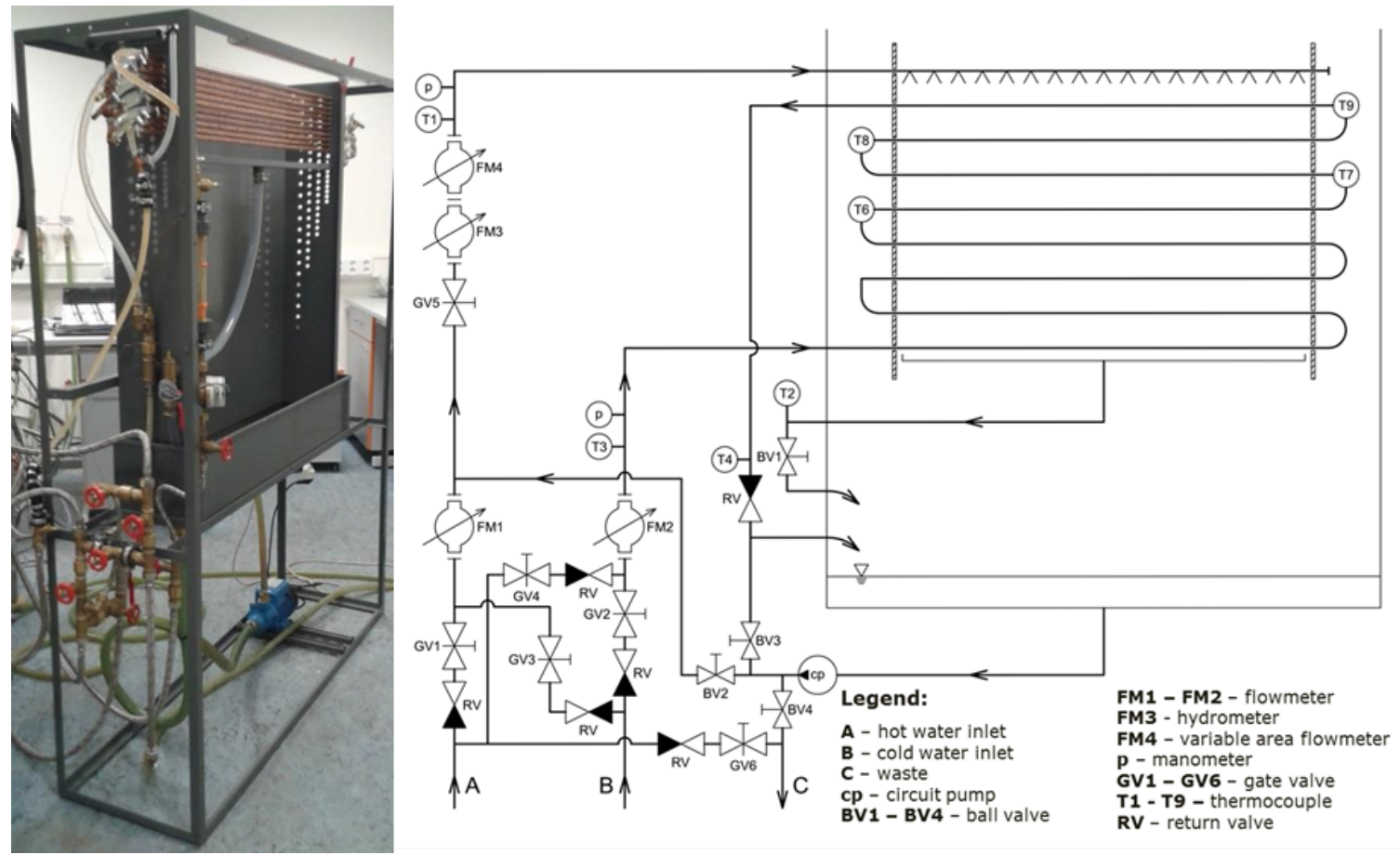

Figure 2. Test Apparatus Diagram.
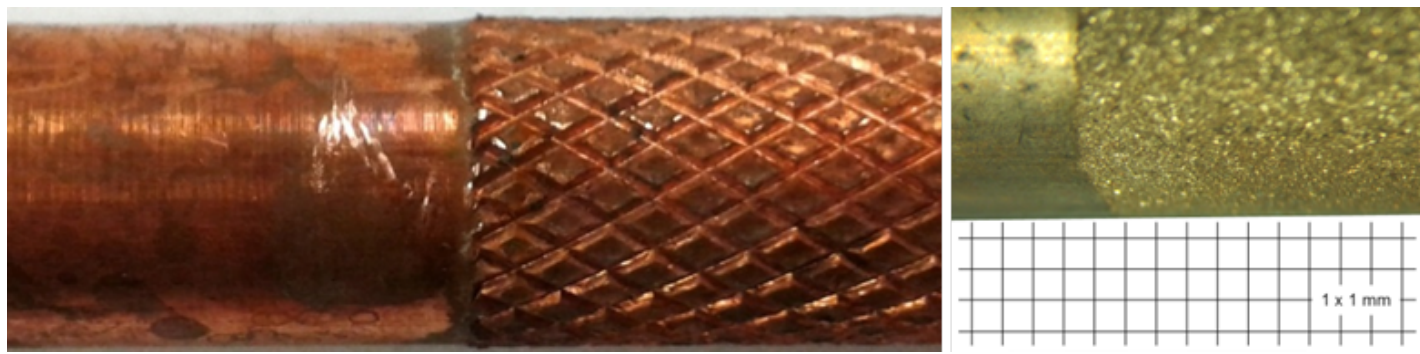

Figure 3. Types of Examined Surfaces.

the law of conservation of energy based on a simplified diagram in Figure 2, Newton's law of heat transfer and Fourier's law of heat conduction.

The evaluation of the measured data is based on the thermal balance between the operation liquid circulating inside the tubes and a sprinkling loop according to the law of conservation of energy. Heat transfer is realized by convection, conduction and radiation. In lower temperatures the heat transferred by radiation is negligible, therefore it is excluded from further calculations. The calculation of the studied heat transfer coefficient is based on the Newton's heat transfer law and Fourier's heat conduction law that have been used to form the following relation

$$
\frac{1}{\alpha_{o}}=2 \pi r_{o}\left(\frac{1}{k_{S}}-\frac{1}{2 \pi \alpha_{i} r_{i}}-\frac{2 \pi \lambda_{S}}{\ln } \frac{r_{o}}{r_{i}}\right)
$$

where $\alpha_{o}\left[\mathrm{~W} \mathrm{~m}^{-2} \mathrm{~K}^{-1}\right]$ is the heat transfer coefficient at the sprinkled tubes' surface; $\alpha_{i}\left[\mathrm{~W} \mathrm{~m}^{-2} \mathrm{~K}^{-1}\right]$ is the heat transfer coefficient at the inner side of a tube set for a fully developed turbulent flow [12, 13]; $r_{o}$ and $r_{i}$ $[\mathrm{m}]$ are the outer and inner tube radii; $\lambda_{S}\left[\mathrm{~W} \mathrm{~m}^{-1} \mathrm{~K}^{-1}\right]$ is thermal conductivity; $k_{S}\left[\mathrm{~W} \mathrm{~m}^{-1} \mathrm{~K}^{-1}\right]$ is heat ad- mittance based on the above mentioned laws governing heat transfer, which is calculated from heat balance of the heating side of the loop, that is why the following must be valid:

$$
Q_{S}^{\prime}=k_{S} L \Lambda T_{\ln }=M_{34}^{\prime} c_{p}\left(p ; \frac{t_{3}+t_{4}}{2}\right)\left(t_{3}-t_{4}\right) .
$$

where $M_{34}^{\prime}\left[\mathrm{kg} \mathrm{s}^{-1}\right]$ is the mass flow of heating water; $c_{p}\left[\mathrm{~J} \mathrm{~kg}^{-1} \mathrm{~K}^{-1}\right]$ is the specific heat capacity of water at constant pressure related to the mean temperature inside the loop; $\mathrm{L}[\mathrm{m}]$ is the total length of the bundle; $\Delta T_{\ln }[\mathrm{K}]$ is a logarithmic temperature gradient where a counter-current exchanger was considered.

\section{Experiment Results}

The experiments described in this paper involved the testing of two temperature differences. It was a range of $15-40{ }^{\circ} \mathrm{C}$ and the range of $15-45^{\circ} \mathrm{C}$ where the falling film liquid's temperature $\mathrm{T} 1$ at the distribution tube outlet was approximately $15^{\circ} \mathrm{C}$ and the temperature of the sprinkled liquid was $\mathrm{T} 340^{\circ} \mathrm{C}$ or $45^{\circ} \mathrm{C}$ at the inlet of an exchanger which consisted of ten tubes 


\begin{tabular}{|c|c|c|c|c|c|c|}
\hline Pitch & $\mathrm{N}$ & $\mathrm{T} 1\left[{ }^{\circ} \mathrm{C}\right]$ & $\mathrm{T} 3\left[{ }^{\circ} \mathrm{C}\right]$ & $\mathrm{V} 1[\mathrm{l} / \mathrm{min}]$ & $\mathrm{V} 2[\mathrm{l} / \mathrm{min}]$ & Error [\%] \\
\hline \multicolumn{7}{|c|}{ Smooth Tubes } \\
\hline $\mathrm{A} 1$ & 772 & $15.0 \pm 0.52$ & $44.9 \pm 0.55$ & $2.1-11.5$ & $7.20 \pm 0.05$ & $3.2 \pm 3.4$ \\
\hline A1 & 2625 & $15.0 \pm 0.44$ & $40.1 \pm 0.55$ & $1.7-13.7$ & $7.22 \pm 0.05$ & $3.0 \pm 2.6$ \\
\hline $\mathrm{A} 2$ & 902 & $14.9 \pm 0.42$ & $45.1 \pm 0.53$ & $2.2-9.0$ & $7.22 \pm 0.05$ & $3.5 \pm 2.9$ \\
\hline $\mathrm{A} 2$ & 690 & $15.4 \pm 0.42$ & $40.1 \pm 0.49$ & $3.0-12.2$ & $7.21 \pm 0.06$ & $5.2 \pm 4.1$ \\
\hline B1 & 927 & $14.8 \pm 0.60$ & $45.3 \pm 0.48$ & $2.1-12.7$ & $7.21 \pm 0.06$ & $3.0 \pm 3.1$ \\
\hline B1 & 1072 & $14.9 \pm 0.48$ & $40.1 \pm 0.58$ & $1.8-12.9$ & $7.21 \pm 0.05$ & $2.6 \pm 2.8$ \\
\hline $\mathrm{C} 1$ & 574 & $15.1 \pm 0.44$ & $45.0 \pm 0.59$ & $3.8-11.0$ & $7.21 \pm 0.06$ & $6.1 \pm 4.4$ \\
\hline $\mathrm{C} 1$ & 777 & $15.2 \pm 0.44$ & $40.1 \pm 0.65$ & $3.8-13.1$ & $7.21 \pm 0.04$ & $5.5 \pm 3.4$ \\
\hline \multicolumn{7}{|c|}{ Groove-Surface Tubes } \\
\hline A1 & 848 & $15.0 \pm 0.50$ & $40.1 \pm 0.62$ & $3.0-11.8$ & $7.21 \pm 0.06$ & $1.9 \pm 1.6$ \\
\hline $\mathrm{A} 1$ & 568 & $14.9 \pm 0.50$ & $45.2 \pm 0.42$ & $3.8-14.9$ & $7.23 \pm 0.04$ & $1.2 \pm 1.8$ \\
\hline $\mathrm{A} 2$ & 1044 & $15.1 \pm 0.44$ & $40.0 \pm 0.49$ & $2.3-13.6$ & $7.21 \pm 0.04$ & $4.9 \pm 4.0$ \\
\hline $\mathrm{A} 2$ & 961 & $14.7 \pm 0.41$ & $45.2 \pm 0.47$ & $1.6-11.8$ & $7.21 \pm 0.05$ & $7.2 \pm 5.9$ \\
\hline B1 & 932 & $15.2 \pm 0.56$ & $40.2 \pm 0.52$ & $2.1-12.8$ & $7.24 \pm 0.13$ & $3.1 \pm 3.6$ \\
\hline B1 & 1043 & $14.8 \pm 0.46$ & $45.1 \pm 0.56$ & $2.1-12.4$ & $7.23 \pm 0.04$ & $2.3 \pm 2.3$ \\
\hline $\mathrm{C} 1$ & 1004 & $15.1 \pm 0.43$ & $40.6 \pm 0.36$ & $2.2-13.4$ & $7.23 \pm 0.05$ & $5.7 \pm 4.2$ \\
\hline $\mathrm{C} 1$ & 553 & $15.0 \pm 0.54$ & $45.2 \pm 0.59$ & $2.0-12.7$ & $7.23 \pm 0.05$ & $4.0 \pm 2.8$ \\
\hline \multicolumn{7}{|c|}{ Sandblasted Tubes } \\
\hline A1 & 573 & $14.7 \pm 0.36$ & $39.7 \pm 0.47$ & $3.1-11.7$ & $7.22 \pm 0.04$ & $2.8 \pm 2.7$ \\
\hline A1 & 1192 & $15.0 \pm 0.47$ & $44.8 \pm 0.59$ & $2.8-14.1$ & $7.21 \pm 0.06$ & $1.9 \pm 1.5$ \\
\hline $\mathrm{A} 2$ & 788 & $15.2 \pm 0.31$ & $39.9 \pm 0.51$ & $1.9-12.2$ & $7.21 \pm 0.06$ & $4.2 \pm 3.5$ \\
\hline $\mathrm{A} 2$ & 252 & $15.1 \pm 0.29$ & $45.0 \pm 0.32$ & $1.2-11.7$ & $7.20 \pm 0.05$ & $5.1 \pm 4.8$ \\
\hline B1 & 1059 & $15.0 \pm 0.35$ & $40.4 \pm 0.34$ & $1.4-12.5$ & $7.20 \pm 0.05$ & $3.3 \pm 2.9$ \\
\hline $\mathrm{C} 1$ & 834 & $15.3 \pm 0.45$ & $40.3 \pm 0.36$ & $2.6-12.7$ & $7.23 \pm 0.05$ & $4.9 \pm 4.2$ \\
\hline
\end{tabular}

TABLE 2. Summary table of measured points; $\mathrm{N}$ is the number of measurement points for each line of the table.

positioned horizontally one above another. Four different tube bundle pitches were studied. These were pitches of $15 \mathrm{~mm}$ (hereinafter marked as A1), $20 \mathrm{~mm}$ (B1), $25 \mathrm{~mm}(\mathrm{C} 1)$ and $30 \mathrm{~mm}(\mathrm{~A} 2)$. The summary in Table 2 also shows, besides the above-mentioned temperature values, the numbers of the measured points, the range of the studied falling film liquid flow rates, the average sprinkled liquid flow rate and the average error for the measured points. In the first case, the studied heat transfer coefficient at the surface of the sprinkled tube bundle was tested for the exchanger consisting of smooth tubes. The measured results for the thermal gradients are shown in Figure 4, on the left for the 15-40 range and on the right for the 15-45 range.

Both thermal gradients feature a linear increase in the heat transfer coefficient up to a falling film liquid flow rate of about 5.0 litres per minute, and the convenience of particular pitch types cannot be assessed due to measurement uncertainty. By reaching the above-mentioned flow rate value, the heat transfer coefficient starts to stabilize at the A2 pitch for both thermal gradients. The heat transfer coefficient at other pitches keeps increasing, although the rise is not so sharp. With a flow rate of approx. 0.6 litres per minute, the heat transfer coefficient stabilizes at the $\mathrm{B} 1$ and $\mathrm{C} 1$ pitches, while the $\mathrm{C} 1$ pitch is more convenient at both thermal gradients. The coefficient keeps increasing at the A1 pitch, and it gets stabilized at the average value of approx. $7.0 \mathrm{~kW} \mathrm{~m}^{2} \mathrm{~K}$, with the maximum tested flow rate reaching 11.2 litres per minute.

In the second case, the exchanger consisted of tubes with a sandblasted surface. The resulting dependences of the heat transfer coefficient on the tube bundle surface are evident in Figure 5, on the left for the 15-40 thermal gradient and on the right for the 15-45 thermal gradient. For the latter only the A1 and A2 pitches have been measured.

Up to a flow rate of approx. 3.5 litres per minute, the heat transfer coefficient at all measured pitches increases within the same trend. The convenience of individual pitches cannot be clearly determined for this type of surface, with the exception of two areas. The first is the B1 pitch and the thermal gradient of 15-40, where the heat transfer coefficient at the flow rate range of $3.5-6.5$ litres per minute is higher by approx. $800 \mathrm{~W} \mathrm{~m}^{2} \mathrm{~K}$ compared to the rest. By reaching 6.5 litres per minute, the heat transfer coefficient stabilizes at the value of approx. $5.0 \mathrm{~kW} \mathrm{~m}^{2} \mathrm{~K}$. The second significant area is located at the A1 pitch and the thermal gradient of $15-45$, with a flow rate higher than 11.5 litres per minute. Within this area, the coefficient stabilizes at the average value 

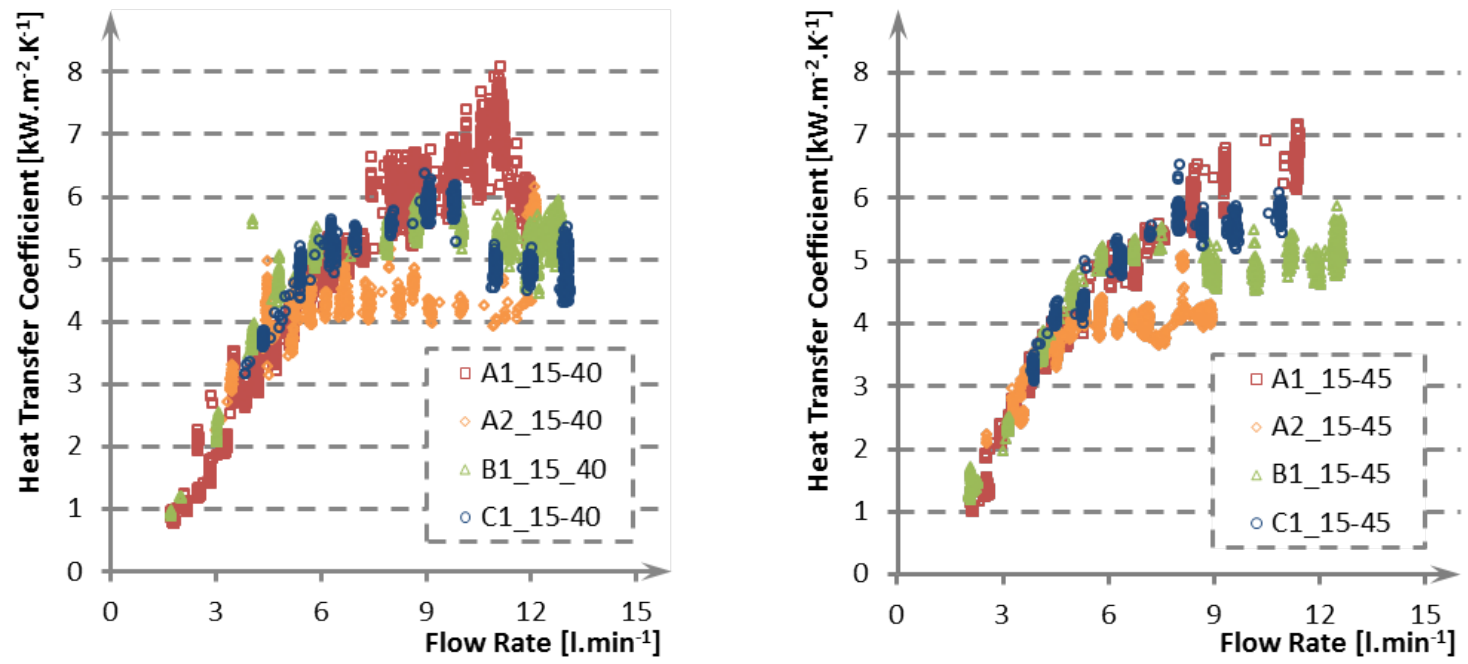

Figure 4. Dependence of Heat Transfer Coefficient on Exchanger Consisting of Smooth Tubes.
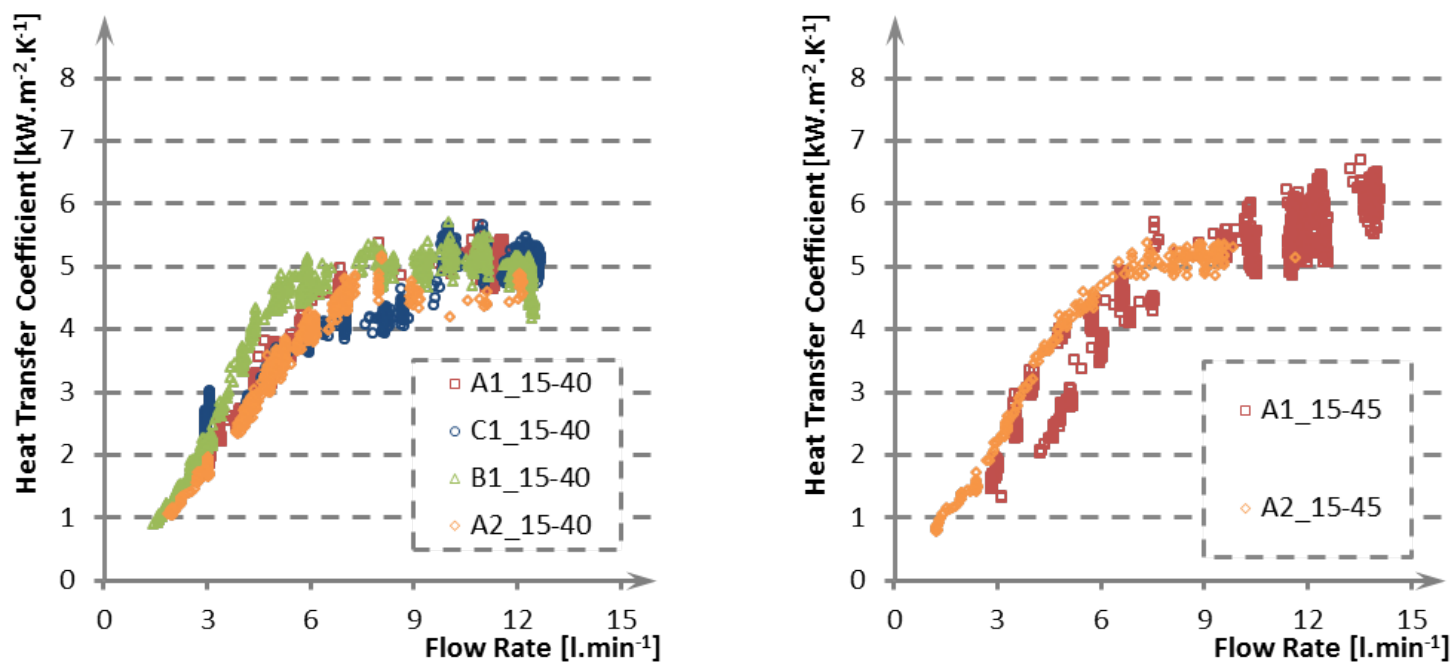

Figure 5. Dependence of Heat Transfer Coefficient on Exchanger Consisting of Sandblasted Tubes.

of approx. $\left.6.0 \mathrm{~kW} \mathrm{~m} \mathrm{~m}^{2} \mathrm{~K}\right)$, which is higher by approx. $1.0 \mathrm{~kW} \mathrm{~m} \mathrm{~m}^{2} \mathrm{~K}$ ) than the coefficient at other pitches.

In the third case, the exchanger consisting of groovesurface tubes has been tested. The resulting dependences of the heat transfer coefficient on the tube bundle surface are shown in Figure 6, on the left for the thermal gradient 15-40, and on the right for the thermal gradient $15-45$.

The results of the tube bundle with a grooved surface again do not clearly imply the most convenient pitch with the exception of two areas. They are in the first case the area at the A2 pitch and the thermal gradient 15-45 that reaches the maximum of approx. $5.0 \mathrm{~kW} \mathrm{~m}^{2} \mathrm{~K}$ in the flow rate range of 5.0 to 10.0 litres per minute, which is in this particular point almost by $2.0 \mathrm{~kW} \mathrm{~m}{ }^{2} \mathrm{~K}$ less in comparison with the rest. The second significant area is at the A1 pitch and both thermal gradients where the average maximum values of the heat transfer coefficient reach almost $8.0 \mathrm{~kW} \mathrm{~m}^{2} \mathrm{~K}$ which is almost by $2.0 \mathrm{~kW} \mathrm{~m}{ }^{2} \mathrm{~K}$ more than at the highest measured parameters.

\section{Conclusions}

This paper presents primary measured values of a heat transfer coefficient at the surface of sprinkled tube bundle consisting of ten tubes positioned horizontally one above another, where the tube pitches have been altered and three various tube surfaces have been tested at two thermal gradients. The primary processing clearly implies the convenience of the groove-surface tubes. When compared to the smooth surface, the increase trend up to the value of approx. 3.0 litres per minute is identical. However, further flow rate increase makes the coefficient at groove-surface tubes rise sharper and the coefficient between some pitches reaches the difference of almost $4.0 \mathrm{~kW} \mathrm{~m}{ }^{2} \mathrm{~K}$.

The comparison of a tube bundle with smooth and sandblasted tubes at the tested thermal gradients surprisingly shows that the heat transfer coefficient at sandblasted tubes is worse, with the maximum value reaching only about $5.0 \mathrm{~kW} \mathrm{~m}{ }^{2} \mathrm{~K}$.

In the introduction of this paper is mentioned, which are published frontiers of the Reynolds number for 

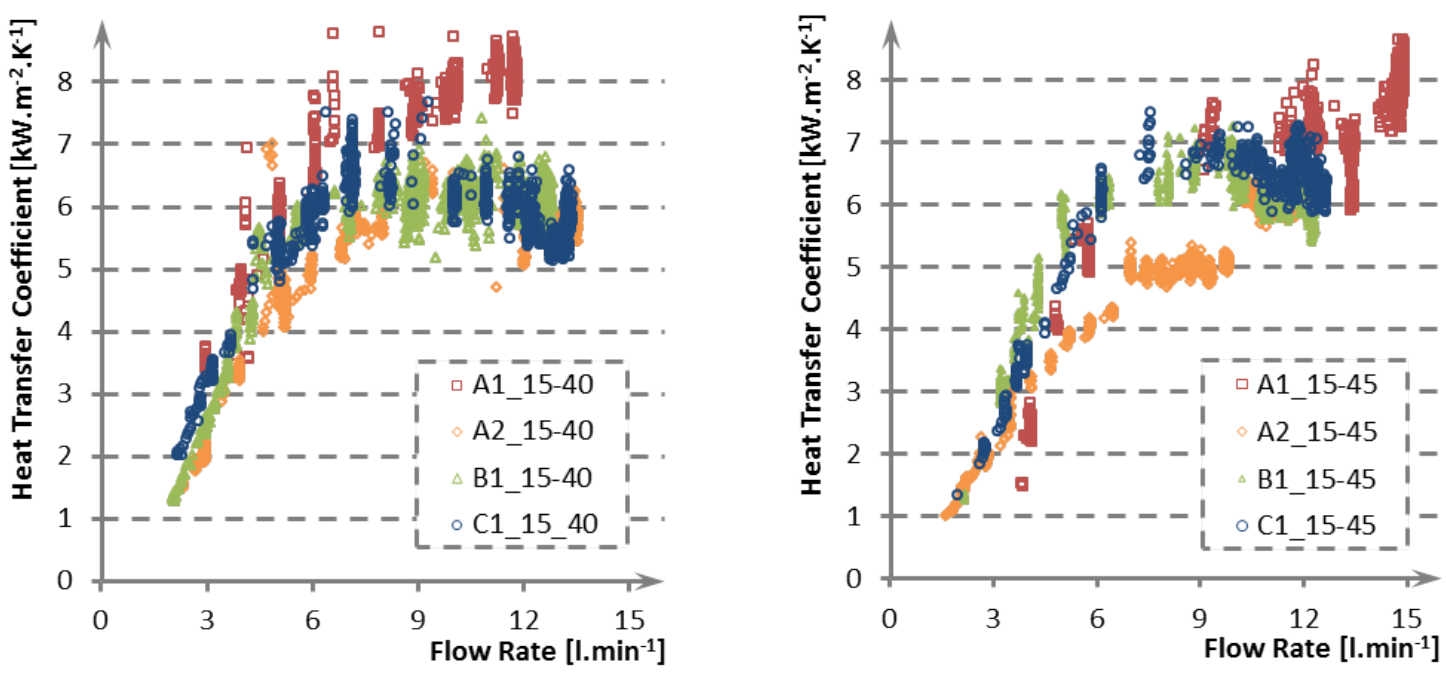

Figure 6. Dependence of Heat Transfer Coefficient on Exchanger Consisting of Groove-Surface Tubes.

sprinkle modes. For the smallest spacing (A1) was achieved fairly good agreement, but with the growing gap between the tubes, there are significant differences which may be caused by structurally different method of water distribution on a tubes bundle. Currently we regimens evaluated very subjective, and therefore the results are not compared numerically.

Our further research should expand these measurements by the effect of low pressure in the tube bundle environment and also by the influence of the exchanger length / number of tubes comprising the exchanger on the heat transfer coefficient at the surface of sprinkled tubes and based on these measurements criterial equations applicable for tube bundle design should be created.

\section{ACKNOWLEDGEMENTS}

This work is an output of research and scientific activities of NETME CENTRE PLUS (LO1202) by financial means from the Ministry of Education, Youth and Sports under the "National Sustainability Programme I".

\section{REFERENCES}

[1] ARMBRUster, R. and J. MitROVIC. Evaporative cooling of a falling water film on horizontal tubes.

Experimental Thermal and Fluid Science. 1998, vol. 18, issue. 3, pp. 183-194. ISSN 08941777.

[2] GONZALEZ, G, J. M, J. M. S JABARDO and W. F. STOECKER. Falling film Ammonia Evaporators. Air Conditioning and Refrigeration Center. College of Engineering. University of Illinois at Urbana-Champaign, 1992, pp. 60.

[3] TANG, J., Z. LU, B. YU-CHI and S. LIN. Droplet Spacing of Falling Film Flow on Horizontal Tube Bundles. In: Proceedings of the 18th International Congress of Refrigeration. Montreal, Quebec, Canada: International Institute of Refrigeration, Paris, France, 1991, pp. 474-478. ISBN 2-9802798-0-3.

[4] YUNG, D., J. J. LORENZ and E. N. GANIĆ. Vapor/Liquid Interaction and Entrainment in Falling
Film Evaporators. Journal of Heat Transfer. 1980, vol. 102 , issue 1 , pp. 20-25.

[5] HU, X. and A. M. JACOBI. The Intertube Falling Film: Part 1 - Flow Characteristics, Mode Transitions, and Hysteresis. Journal of Heat Transfer. 1996, vol. 118, issue. 3, pp. 616-624. ISSN 0022-1481. DOI:10.1115/1.2822676.

[6] JAFAR, THORPE and TURAN. Computational fluid dynamics seventh international conference on CFD in the minerals and process industries. Melbourne, Vic.: CSIRO, 2009. ISBN 978-064-3098-251.

[7] WANG, Xiaofei, P. S. HRNJAK, S. ELBEL, A. M. JACOBI and Maogang HE. Flow Patterns and Mode Transitions for Falling Films on Flat Tubes. Journal of Heat Transfer. 2012, vol. 134, issue 2, pp. 1-8. DOI:10.1115/1.4005095.

[8] PARKEN, W. H., L. S. FLETCHER, V. SERNAS and J. C. HAN. Heat Transfer Through Falling Film Evaporation and Boiling on Horizontal Tubes. Journal of Heat Transfer. 1990, vol. 112, issue 3, pp. 744-750. DOI:10.1115/1.2910449.

[9] OWENS, W. L. Correlation of thin film evaporation heat transfer coefficients for horizontal tubes. Proceedings, Fifth Ocean Thermal Energy Conversion Conference, Miami Beach, Florida. 1978, pp. 71-89.

[10] SERNAS, V. Heat Transfer Correlation for Subcooled Water Films on Horizontal Tubes. Journal of Heat Transfer. 1979, vol. 101, issue 1, pp. 176-178.

[11] X-ENG. X Steam Tables for MS Excel [computer file .xls]. Ver. 2.6.. [cit. 30.11.2010]. Freeware. http://www.x-eng.com/XSteam_Excel.htm [2010-11-30].

[12] INCROPERA Frank.P., DEWITTL David.P., BERGMAN T., LAVINE, A. Fundamentals of Heat and Mass Transfer, 6th Edition, 2007, Hard cover, 1024 pages, ISBN 978-0-471-45728-2

[13] Jícha, Miroslav (2001). Přenos tepla a látky. 1. vyd. Brno: CERM. 